\title{
A VEZ E A VOZ DOS COORDENADORES DAS CPAS DAS IES DE CAMPINAS QUE INTEGRAM O SINAES
}

\author{
Rosana Augusto* \\ Newton Cesar Balzan**
}

Recebido em: 23/05/07

Avaliado em: 20/09/07

\begin{abstract}
* Mestrado em Educação pela PUC-Campinas. Profa. e Coord. do Curso de Administração do Instituto de Ensino Superior de Americana.E-mail: rosana.augusto@gmail.com

** Pós-Doutorado pela Boston University, USA; Prof. Titular, Faculdade de Educação-PUC-Campinas. Prof. Colaborador junto à Faculdade de Educação-Unicamp; Assessor CNPq, FAPESP, CAPES. Bolsista, CNPq, Nível 1-A

E-mail: nbalzan@uol.com.br
\end{abstract}

Resumo: Este artigo tem como objetivo apresentar o trabalho das Comissões Próprias de Avaliação das Instituições de Ensino Superior de Campinas, que integram o Sistema Nacional de Avaliação da Educação Superior (SINAES), a partir da visão de um ator fundamental nesse processo - o coordenador -, que em conjunto com os demais membros da comissão coordenaram o processo de auto-avaliação institucional. Procura-se conhecer como foram coordenados esses trabalhos, quem são os coordenadores, como eles concebem a avaliação institucional e o que esperam do atual sistema avaliativo.

Palavras-chave: Avaliação Institucional; SINAES; Comissões Próprias de Avaliação; Auto-Avaliação; Avaliação Interna.

The voice of the Campinas Higher Education

Institutions' Internal Evaluation Commission Coordinators

Abstract: The purpose of this article is to present the work done by the Internal Evaluation Commissions of Higher Education Institutions of Campinas that integrate the National Higher Education Evaluation System (SINAES), from the point of view of a fundamental actor - the coordinator - who, along with the institutional assessment team, is responsible for the institution's self evaluation process. The main focus of this work is to investigate how the evaluation process is coordinated. Additionally, the research investigated who the coordinators are, what are their expectations and how the institutional evaluation process was conceived.

Key words: Institutional Evaluation; SINAES; Internal Evaluation Commissions; Self Evaluation; Internal Evaluation. 


\section{Introdução}

O processo de globalização vem provocando mudanças mundiais na sociedade contemporânea de uma forma geral, alterando, sobremaneira, o modo de ser e fazer da universidade brasileira e, desde então, vêm provocando muitas mudanças no ensino.

Uma dessas mudanças se deve ao fato de que a globalização generalizou várias práticas referentes ao funcionamento do sistema da educação superior por todo o mundo, e a avaliação da educação nesse nível de ensino foi uma delas.

A Avaliação da Educação Superior é recente e está relacionada à qualidade da educação nesse nível de ensino, e também vinculada às políticas econômicas e, conseqüentemente, às políticas educacionais, entre outros fatores.

Nos anos 1990, junto com as políticas governamentais neoliberais, houve um aumento considerável nas publicações nessa área, principalmente a partir da segunda metade do período, devido ao papel central que a avaliação institucional passou a ocupar nas políticas públicas de educação.

No Brasil, a primeira proposta de Avaliação Institucional da educação superior, nos cursos de graduação, surgiu, em 1983, com o Programa de Avaliação da Reforma Universitária (PARU), contudo, foi a partir dos anos 1990 que a discussão a respeito dessa temática se intensificou e ganhou relevo no meio acadêmico, político e social.

Em 1993, surgiu o Programa de Avaliação Institucional das Universidades Brasileiras (PAIUB), de caráter democrático e participativo, vigorando oficialmente até 2003. Contudo, a partir de 1995, ele passou a perder sua identidade e ser aplicado como instrumento de avaliação interna, surgindo o Exame Nacional de Cursos (ENC).

O ENC, ou Provão como ficou mais conhecido, foi implementado durante o Governo Fernando Henrique Cardoso, para atender a interesses neoliberais. Ele não era um sistema de Avaliação Institucional, mas, sim, um instrumento pontual e estático, uma vez que era uma "prova" aplicada aos alunos concluintes dos cursos de graduação previamente selecionados e que buscava medir o desempenho desses alunos. Apesar das inúmeras críticas atribuídas a esse "sistema", ele se manteve em vigor até 2003.

O Presidente Luiz Inácio Lula da Silva iniciou seu mandato no ano de 2003, porém foi em abril de 2004, que foi criado o Sistema Nacional de Avaliação da Educação Superior (SINAES), que está em vigência. 
Nesse sistema, a avaliação é concebida como instrumento de política educacional objetivando a sustentação da qualidade do sistema de educação superior.

Os três principais elementos que compõem o SINAES são: a avaliação das instituições, dos cursos e do desempenho dos estudantes. Esse sistema avalia todos os aspectos que estão relacionados com o ensino, a pesquisa, a extensão, a responsabilidade social, o desempenho dos discentes, a gestão institucional, o corpo docente, as instalações, entre outros.

É um sistema integrado que busca cruzar informações nas diversas dimensões da instituição, visando realizar uma avaliação sistêmica e não pontual.

O SINAES apresenta condições para atingir seus objetivos, porém se trata de um sistema relativamente novo, o qual está em fase inicial de desenvolvimento, não sendo possível estudar a sua aplicação prática na íntegra.

Devido a essa limitação, o presente artigo está centrado no trabalho das Comissões Próprias de Avaliação (CPAs), das Instituições de Ensino Superior de Campinas, que integram o SINAES, a partir da visão de um ator fundamental nesse processo, o seu coordenador. Contudo, salienta-se que apesar de relevante ele não é o único, mas, sim, um dos componentes da comissão.

É importante destacar que, a concepção equivocada a respeito do SINAES e/ou a utilização inadequada dos instrumentos de coleta, em qualquer uma de suas fases, pode se traduzir em resultados ineficientes, comprometendo o bom funcionamento de todo o sistema.

\section{Breve Histórico da Avaliação Institucional no Brasil}

Nos anos 1983, surge a primeira proposta de avaliação da educação superior brasileira na graduação, com a criação do PARU - Programa de Avaliação da Reforma Universitária (SINAES, 2004b).

Um dos objetivos do PARU era garantir a qualidade dos cursos de graduação, uma vez que, na década de 1970, houve uma grande expansão de instituições, cursos e alunos nesse nível de ensino.

Na Nova República, mais precisamente em 1985, o Presidente José Sarney criou uma Comissão Nacional para a Reformulação da Educação Superior, que apresentou a conclusão de seus trabalhos no documento intitulado "Uma Nova Política para a Educação Brasileira". 
Nos anos 1990, junto com as políticas governamentais neoliberais, houve um crescimento considerável de publicações nessa área, especialmente a partir da segunda metade do período, sinalizando não apenas o interesse, mas também o papel central que essa temática passou a ocupar no âmbito das reformas e das políticas públicas de educação (SINAES, 2004a).

Em 1993, o MEC, por iniciativa da comunidade universitária, criou a Comissão Nacional de Avaliação e o seu Comitê Assessor. Ambos eram compostos por representantes da comunidade científica, que idealizaram e começaram a implementar o Programa de Avaliação Institucional das Universidades Brasileiras (PAIUB).

O PAIUB se configurou na primeira proposta avaliativa de caráter formativo proposta pelo Governo Federal. Ele concebia a auto-avaliação como fase inicial de um processo que completava o ciclo com a avaliação externa. Sua experiência foi curta, porém conseguiu legitimar a cultura da avaliação e realizar mudanças na dinâmica das universidades. Apesar de ter recebido uma grande adesão por parte das universidades, a sua implementação foi afetada pela falta de apoio do MEC e, a partir de 1995, começou a ser fragilizado, até que as sucessivas alterações na legislação, o transformaram em um processo meramente interno nas instituições (SINAES, 2004b).

No governo neoliberal do Presidente Fernando Henrique Cardoso (1995-2002), o então Ministro da Educação, Paulo Renato Souza, iniciou outro processo de institucionalização das práticas avaliativas para a educação superior, bastante diferenciado das bases do PAIUB, pois a Política de Estado, naquele momento, era outra.

A partir da promulgação da Lei $n^{\circ} 9.131 / 95$, e posteriormente com a Lei n ${ }^{\circ}$ 9.394/1996, conhecida como Lei de Diretrizes e Bases da Educação Nacional, novos e sucessivos mecanismos de avaliação foram implementados, sendo eles, além do Exame Nacional de Cursos (ENC); o Questionário referente às condições socioeconômicas do discente e suas opiniões a respeito das condições de ensino de seu curso; a Análise das condições de Ensino (ACE); a Avaliação das Condições de Oferta (ACO), e Avaliação Institucional dos Centros Universitários. (SINAES, 2004b).

Estavam presentes no cenário nacional da educação superior, daquela época, dois formatos de avaliação o PAIUB e o ENC. O primeiro, estava comprometido com a transformação acadêmica em uma perspectiva formativa/emancipatória. O outro possuía uma concepção regulatória e 
estava relacionado ao controle de resultados e do valor de mercado (SINAES 2004b).

A presença simultânea desses dois mecanismos de avaliação que apresentavam concepções, ideologias, valores e interesses conflitantes, sinalizava a influência que o país estava sofrendo de organismos financeiros internacionais, como o Banco Mundial, que fomentava uma política fiscalizadora, em atendimento aos interesses de países centrais.

Rothen e Schulz (2007) comentam que no discurso oficial, o Provão era apresentado como um dos instrumentos na avaliação das IES, mas, na realidade, ele era um instrumento quase exclusivo, tanto que o resultado desse exame era amplamente divulgado, o que não acontecia com o resultado das outras avaliações.

Assim, apesar de todas as severas e contundentes críticas tecidas ao ENC, ele se manteve por quase uma década, sendo o primeiro provão realizado no ano de 1996 e o último, em 2003.

No ano de 2003, no primeiro mandato do Presidente Luiz Inácio Lula da Silva, foi instituída, pelo então Ministro da Educação, Cristovam Buarque, uma Comissão Especial de Avaliação (CEA).

O objetivo da CEA era analisar, subsidiar, recomendar, propor critérios e estratégias para reformular os processos e políticas de avaliação da Educação Superior e, ainda, elaborar uma revisão crítica dos instrumentos metodologias e critérios que estavam sendo utilizados (CONAES, 2004).

Em 27 de agosto de 2003, a CEA, presidida pelo Professor José Dias Sobrinho, apresentou um relatório final intitulado "Sistema Nacional de Avaliação da Educação Superior - SINAES: Bases para uma nova proposta de Avaliação da Educação Superior" ao Ministro da Educação (SINAES, 2004b).

A proposta original da CEA sofreu alguns ajustes, gerando outra proposta conhecida como Sistema Nacional de Avaliação e Progresso do Ensino Superior (SINAPES), instituída pela Medida Provisória nº 147, de 15 de dezembro de 2003.

Na primeira reforma ministerial do Governo Lula, em 27de janeiro de 2004, o Ministro da Educação, Cristovam Buarque, foi substituído por Tarso Genro $^{1}$ que, apenas alguns meses após sua posse, apresentou uma nova proposta.

$1 \mathrm{O}$ atual Ministro da Educação, Fernando Haddad, assumiu o Ministério em julho de 2005. 
A proposta apresentada por Tarso Genro contemplava tanto aspectos da formulação da proposta original do SINAES elaborada pela CEA, quanto os aspectos do SINAPES. Surge, então, o SINAES nos moldes atualmente em vigência.

Diante do exposto, pode-se afirmar que o SINAES, como política de Estado que tem caráter de regulação e emancipação, é um sistema misto que possui tanto as características de avaliação emancipatória, preservadas do documento da CEA e que são muito similares aos princípios do PAIUB, possibilitando que as instituições participem do processo avaliativo da instituição, quanto às características da avaliação regulatória, que podem ser percebidas na própria Lei que o criou, na medida em que há o controle no credenciamento e recredenciamento dos cursos, por exemplo.

\section{O SINAES}

O SINAES foi oficialmente instituído no dia 14 de abril de 2004, com a promulgação da Lei $\mathrm{n}^{\circ} 10.861$, a qual foi publicada no Diário Oficial da União (DOU) n 72 , no dia 15 de abril de 2004, na seção 01 e páginas 3-4.

De acordo com a CONAES (2004), esse sistema avaliativo é parte de uma política governamental responsável pela educação superior brasileira, tendo como núcleo a formulação de estratégias e de instrumentos para melhorar a qualidade e a relevância desse nível de educação nas atividades de ensino, pesquisa e extensão. Ele deve integrar e articular de maneira coerente, concepções, objetivos, metodologias, práticas e atores da comunidade acadêmica e de esferas governamentais.

O SINAES, pela sua concepção, segundo a CONAES (2004, p.13), tem como princípios fundamentais:

- A responsabilidade social com a educação superior;

- O reconhecimento da diversidade do sistema;

- O respeito à identidade, à missão e à história das instituições;

- A globalidade institucional pela utilização de um conjunto significativo de indicadores considerados em sua relação orgânica;

- A continuidade do processo avaliativo como instrumento de política educacional para cada instituição e o sistema de educação superior em seu conjunto. 
No SINAES, todos os processos avaliativos são coordenados e supervisionados pela Comissão Nacional de Avaliação da Educação Superior (CONAES), ficando a parte operacional do sistema sob a responsabilidade do INEP.

Entre os seus objetivos destacam-se: "identificar mérito e valor das instituições, áreas, cursos e programas nas dimensões de ensino, pesquisa, extensão, gestão e formação; melhorar a qualidade da educação superior, orientar a expansão da oferta; promover a responsabilidade social das IES, respeitando a identidade institucional e a autonomia" (SINAES, 2006a).

De acordo com o SINAES (2004b, p. 83-84), esse sistema "busca assegurar, entre outras coisas, a integração das dimensões internas e externas, particular e global, somativo e formativo, quantitativo e qualitativo e os diversos objetos e objetivos da avaliação".

Segundo a concepção do SINAES - Lei $n^{\circ} 10.861$, no artigo $3^{\circ}$ - a avaliação das instituições de educação, para atingir seus objetivos, deve considerar diferentes dimensões institucionais, sendo as dez dimensões obrigatórias:

I - a missão e o plano de desenvolvimento institucional;

II - a política para o ensino, a pesquisa, a pós-graduação, a extensão e as respectivas formas de operacionalização, incluídos os procedimentos para estímulo à produção acadêmica, as bolsas de pesquisa, de monitoria e demais modalidades;

III - a responsabilidade social da instituição, considerada especialmente no que se refere à sua contribuição em relação à inclusão social, ao desenvolvimento econômico e social, à defesa do meio ambiente, da memória cultural, da produção artística e do patrimônio cultural;

IV - a comunicação com a sociedade;

V - as políticas de pessoal, as carreiras do corpo docente e do corpo técnico-administrativo, seu aperfeiçoamento, desenvolvimento profissional e suas condições de trabalho;

VI - organização e gestão da instituição, especialmente o funcionamento e representatividade dos colegiados, sua independência e autonomia na relação com a mantenedora, e a participação dos segmentos da comunidade universitária nos processos decisórios;

VII - infra-estrutura física, especialmente a de ensino e de pesquisa, biblioteca, recursos de informação e comunicação; 
VIII - planejamento e avaliação, especialmente os processos, resultados e eficácia da auto-avaliação institucional;

IX - políticas de atendimento aos estudantes;

$X$ - sustentabilidade financeira, tendo em vista o significado social da continuidade dos compromissos na oferta da educação superior.

As características fundamentais desse sistema, de acordo com a CONAES (2004), são: a avaliação institucional como centro do processo avaliativo; a integração de vários instrumentos embasados em uma concepção global e o respeito à identidade e à diversidade das instituições.

O SINAES é um sistema global e integrado das atividades acadêmicas, constituído de três elementos principais: a) Avaliação das Instituições de Educação Superior (AVALIES), composta pelas avaliações interna e externa das instituições; b) Avaliação dos cursos de Graduação (ACG), realizada pelas comissões destinadas para este fim; c) Avaliação de Desempenho dos Estudantes, realizada mediante a participação por amostragem dos ingressantes e concluintes de cursos previamente selecionados a cada ano para a realização do Exame Nacional de Desempenho dos Estudantes (ENADE).

Esses três componentes, segundo a CONAES (2004), fazem parte do mesmo sistema de avaliação, porém cada um desses processos acontece em situações e momentos diferentes, utilizando-se de instrumentos próprios, mas articulados entre si. Cada um aborda dimensões e indicadores específicos, com a finalidade de identificar os pontos fortes e fracos dos cursos e instituições, promovendo a melhoria da sua qualidade e relevância e, consequientemente, melhorando a formação dos educandos, além de fornecer à sociedade informações a respeito da educação superior brasileira. Esses três elementos essenciais que integram o SINAES serão detalhados na sequiência.

\section{I) Avaliação de Cursos de Graduação (ACG)}

De acordo com o SINAES (2004c), a avaliação dos cursos de graduação ocorre por instrumentos e procedimentos que incluem visitas in loco de comissões externas e a periodicidade desta avaliação depende do processo de reconhecimento e renovação de reconhecimento dos cursos.

Esta avaliação é uma medida necessária para a emissão de diplomas e passou a ser realizada de forma periódica com a finalidade de cumprir o 
determinado na Lei de Diretrizes e Bases da Educação Superior, objetivando garantir a qualidade do ensino oferecido pelas IES.

Segundo o INEP (2006b), a instituição deve preencher um formulário eletrônico composto por três grandes dimensões: a qualidade do corpo docente, a organização didático-pedagógica e as instalações físicas, com ênfase na biblioteca, possibilitando uma análise prévia pelos avaliadores da situação dos cursos e permite, dessa forma, uma melhor verificação in loco.

Em síntese, a avaliação dos cursos de graduação visa identificar as condições de ensino oferecidas, perfil do corpo docente, instalações físicas e organização didático-pedagógica.

Recentemente, o Calendário de avaliações do Ciclo Avaliativo do Sistema Nacional de Avaliação da Educação Superior - SINAES para o triênio 2007/2009 foi estabelecido pelo Ministro da Educação, por meio da Portaria Normativa $\mathrm{n}^{\circ} 1$, de 10 de janeiro de 2007 , que entre outras providencias menciona em seu artigo $1^{\circ}$ que serão avaliados, em 2007, os cursos das áreas participantes do ENADE 2004; em 2008, os que participaram do ENADE 2005; e, em 2009, os que participaram do ENADE 2006.

\section{II) Avaliação de Desempenho dos Estudantes}

A avaliação do desempenho dos discentes dos cursos de graduação é outro instrumento do SINAES que, por meio do Exame Nacional de Desempenho dos Estudantes (ENADE), tem o objetivo de aferir o desempenho dos alunos em relação ao conteúdo programático, suas habilidades e competências.

O ENADE é considerado componente curricular obrigatório dos cursos, de acordo com a Lei ${ }^{\circ} 10.861$, de 14 de abril de 2004, Art. $5^{\circ}, \S 5^{\circ}$, aplicado aos discentes do final do primeiro e do último ano do curso ${ }^{2}$, por meio de procedimentos amostrais.

Dessa maneira, pretende verificar como o aluno entra na instituição e como ele está saindo da instituição, com a finalidade de perceber o quanto aquela instituição colaborou para formação daquele educando.

2 Em 2006, segundo o INEP (2006a), se enquadrariam como alunos do primeiro ano do curso aqueles que até o dia 1o de agosto tivessem concluído entre 7\% e 22\% (inclusive) da carga horária mínima do currículo do curso da instituição. Seriam considerados alunos do último ano do curso aqueles que, até a referida data, tivessem concluído, ao menos, $80 \%$ da carga horária mínima do currículo dos cursos da IES ou aqueles que tivessem condições acadêmicas de conclusão do curso de graduação durante o ano letivo de 2006. 
Esse instrumento avalia os cursos de graduação em ciclos de três anos, ou seja, a cada ano, novas áreas são avaliadas.

Em 2004, os primeiros cursos a participar do ENADE foram: Agronomia, Educação Física, Enfermagem, Farmácia, Fisioterapia, Fonoaudiologia, Medicina, Medicina Veterinária, Nutrição, Odontologia, Serviço Social, Terapia Ocupacional e Zootecnia (INEP, 2006a).

No ano de 2005, participaram do ENADE os cursos de Arquitetura e Urbanismo, Biologia, Ciências Sociais, Computação, Engenharia, Filosofia, Física, Geografia, História, Letras, Matemática, Pedagogia e Química (INEP 2006a).

Os cursos selecionados, em 2006, para o ENADE foram: Administração, Arquivologia, Biblioteconomia, Biomedicina, Ciências Contábeis, Ciências Econômicas, Comunicação Social, Design, Direito, Formação de Professores da Educação Básica (Formação de professor das séries iniciais do ensino fundamental, Formação de professor do ensino fundamental e Normal Superior), Música, Psicologia, Secretariado Executivo, Teatro e Turismo (INEP 2006a).

Conforme já mencionado, o ENADE tem ciclos trienais de avaliação. Dessa forma, o primeiro ciclo foi completado em 2006, fazendo com que, no ano de 2007, participe do ENADE uma amostragem representativa de alunos concluintes e ingressantes de cursos que já foram avaliados.

No ano de 2007, devido ao início de um novo ciclo trienal de avaliação dos cursos, foram selecionados para avaliação os mesmos 13 cursos do ano de 2004, já mencionados, os quais pertencem, em sua maioria, à área da Saúde e ainda o curso de Biomedicina, que foi avaliado em 2006, mas por ser considerada uma carreira vinculada à área da Saúde, o curso será avaliado novamente (INEP, 2007).

A inscrição de todos os alunos que se enquadram nos critérios para a realização do ENADE é de responsabilidade das suas respectivas IES. Uma vez inscritos todos os alunos da IES regularmente matriculados e considerados ingressantes ou concluintes dos cursos selecionados, passam para a fase seguinte.

Em uma segunda etapa, o INEP seleciona por amostragem e divulga os alunos selecionados para a realização do Exame. Esses alunos recebem, em sua residência, a data, horário, local das provas e, também, um questionário socioeconômico acompanhado de um gabarito de respostas que deve ser entregue na oportunidade de realização do exame. 
A VEZ E A VOZ DOS COORDENADORES DAS CPAS DAS IES DE CAMPINAS QUE INTEGRAM O SINAES

Esse questionário é composto por 103 (cento e três) itens de múltipla escolha e, segundo consta no próprio corpo do questionário, essa pesquisa é parte integrante do ENADE, tendo por objetivos traçar o perfil dos alunos (ingressantes ou concluintes) dos cursos de graduação; conhecer a opinião dos educandos a respeito do ambiente acadêmico em que estão inseridos; e consolidar informações para promover a melhoria das condições de ensino e também dos procedimentos didático-pedagógico das IES.

O desempenho individual do aluno é sigiloso, sendo divulgado apenas a ele por meio de documento enviado para sua residência. Em seu histórico escolar a única informação anotada é se o aluno foi dispensado oficialmente pelo INEP da realização do ENADE ou a data em que realizou o exame.

É importante destacar que se o discente for selecionado e não comparecer para a realização do ENADE estará em situação irregular perante o MEC devido à obrigatoriedade desse componente curricular e, enquanto isso não for regularizado junto a esse órgão governamental, o aluno não pode ser graduado.

O INEP, antes de fechar o primeiro ciclo de avaliação dos cursos de graduação, deu prazo para as IES até 4 de outubro de 2006, para informar o nome dos alunos que haviam faltado ao ENADE 2004 e 2005, com a finalidade de que os mesmos participassem do ENADE 2006, regularizando sua situação perante o MEC.

Após a realização de cada ENADE, os coordenadores dos cursos avaliados respondem a um questionário digital para o INEP, em seu site, composto de 44 questões alternativas, sendo 07 referentes ao Perfil do Coordenador do Curso, 05 sobre Instalações para funcionamento do curso, 02 sobre a Administração Acadêmica, 03 sobre o projeto do curso, 10 sobre as competências desenvolvidas pelas disciplinas do curso, 04 sobre Atividades articuladas ao ensino de graduação, e um último bloco de questões com 13 perguntas sobre vários aspectos (práticas pedagógicas e instalações, por exemplo) as quais não são agrupadas por tema.

Comentam Ristoff e Limana (2007) que, muitas dessas perguntas que são feitas aos coordenadores de curso são também feitas aos estudantes, para que se faça um estudo comparativo entre a compreensão que os discentes têm do curso e de seu coordenador, e a compreensão que o coordenador do curso tem dos discentes e do curso como um todo, abrin- 
do oportunidades bastante interessantes para estudos de auto-orientação acadêmica.

Vale salientar que, diferente do que ocorria no Provão, o ENADE não é o único mecanismo de avaliação para se verificar a qualidade dos cursos e da instituição, mas, sim, mais um instrumento para auxiliar nesse diagnóstico e dessa feita, deve ser analisado sempre dentro do contexto do sistema avaliativo e não de maneira isolada.

\section{III) Avaliação das Instituições de Educação Superior (AVALIES)}

A avaliação das instituições busca identificar o perfil da instituição e o significado da sua atuação, por meio das atividades, cursos, programas, projetos e setores, respeitando a diversidade e as especificidades das diferentes organizações acadêmicas.

Esse processo avaliativo, conforme a CONAES (2004), tem caráter de construção e ajuste de estratégias e metodologias pelas próprias IES. Deve, porém, gerar as características de comparabilidade entre todas as instituições do sistema, no decorrer de sua implementação.

A AVALIES, de acordo com SINAES (2004c), é o centro de referência e articulação do sistema de avaliação, desenvolvendo-se em duas fases principais: a avaliação interna ou auto-avaliação e a avaliação externa, detalhadas a seguir.

\section{a) Auto-Avaliação das Instituições}

A avaliação interna é um processo contínuo em que a instituição busca se autoconhecer com vistas ao aperfeiçoamento de suas atividades acadêmicas, objetivando melhorar a qualidade educativa e alcançar relevância social.

De acordo com a CONAES (2004), a avaliação interna é um processo em que um curso ou uma instituição faz uma análise interna sobre o que deseja ser, o que de fato realiza, como se organiza, administra e age, visando a busca sistematizada de informações para realizar a análise e interpretação dessas informações, procurando identificar práticas exitosas, bem como a percepção de omissões e equívocos, com a finalidade de evitá-los futuramente. 
A VEZ E A VOZ DOS COORDENADORES DAS CPAS DAS IES DE CAMPINAS QUE INTEGRAM O SINAES

De acordo com a CONAES (2004, p.20), a avaliação interna, respeitando a diversidade da missão de cada instituição, tem como objetivos principais:

- Avaliar a instituição como uma totalidade integrada que permite a auto-análise valorativa da coerência entre a missão e as políticas institucionais efetivamente realizadas, visando a melhoria da qualidade acadêmica e o desenvolvimento institucional.

- Privilegiar o conceito da auto-avaliação e sua prática educativa para gerar, nos membros da comunidade acadêmica, autoconsciência de suas qualidades, problemas e desafios para o presente e o futuro, estabelecendo mecanismos institucionalizados e participativos para a sua realização.

Em conformidade com a CONAES (2004), para que o processo de avaliação interna possa obter bons resultados, é necessário que haja os seguintes requisitos fundamentais: existência de uma equipe de coordenação; participação dos integrantes da instituição; compromisso explícito por parte dos dirigentes das IES, informações válidas e confiáveis; e o uso efetivo dos resultados.

Para que se consiga eficiência na auto-avaliação, é necessário que se realize um planejamento das ações mediante um plano de trabalho que, em seu cronograma, contemple as atividades a serem desenvolvidas e a distribuição das tarefas e dos recursos humanos, materiais, operacionais, etc.(CONAES, 2004).

Cada instituição deve elaborar a metodologia de trabalho, os procedimentos e os objetivos do seu processo de auto-avaliação, respeitando a sua especificidade e dimensão, estando apoiadas nas diretrizes estabelecidas pela CONAES.

A auto-avaliação é entendida no SINAES como um processo cíclico, criativo e renovador de análise e síntese das dimensões que definem a instituição.

O processo contínuo de auto-avaliação será um instrumento de construção e ou consolidação da cultura de avaliação na instituição, em que a comunidade interna se identificará e se comprometerá. O caráter formativo deve possibilitar o aperfeiçoamento tanto pessoal dos membros da comunidade acadêmica, quanto institucional, pelo fato de fazer com que todos os envolvidos se coloquem em um processo de reflexão e autoconsciência institucional (CONAES, 2004). 
A Avaliação interna ou Auto-avaliação é realizada pela Comissão Própria de Avaliação (CPA) de cada IES, de acordo com as "Diretrizes para a Avaliação das instituições de Educação Superior" e pelo "Roteiro de auto-avaliação institucional", da CONAES.

Esses documentos estabelecem que os trabalhos de auto-avaliação das CPAS devem ser realizados em três etapas: preparação; desenvolvimento e consolidação, as quais são sub-divididas em fases.

A primeira etapa, conhecida como preparação, é composta por três fases: constituição da CPA; planejamento dos trabalhos e sensibilização interna.

No planejamento, segundo o SINAES (2004c), a CPA deve elaborar o projeto de auto-avaliação, definindo objetivos, metodologia, estratégias, recursos necessários e cronograma de ações avaliativas. Esse planejamento deve ser discutido junto à comunidade acadêmica, considerando-se as especificidades da instituição.

$\mathrm{Na}$ sensibilização, a CPA deve buscar o envolvimento de toda a comunidade acadêmica para elaborar a proposta de avaliação, podendo, para tal, utilizar-se de seminários, reuniões, palestras, entre outros. A sensibilização deve ser freqüente durante todo processo avaliativo, pois haverá sempre novos sujeitos ingressando na comunidade acadêmica (SINAES, 2004c).

A segunda etapa é a de desenvolvimento, que busca garantir a coerência entre as ações planejadas e as metodologias escolhidas, a articulação entre os participantes e a observação dos prazos previstos no cronograma.

Nessa etapa, conforme a CONAES (2004, p. 26), são desenvolvidas as seguintes atividades:

- implementar os procedimentos de coleta e análise das informações, conforme definidos no Projeto de Avaliação SINAES, em consonância com as propostas contidas no documento Orientações Gerais;

- elaborar relatórios parciais relativos às diferentes etapas de autoavaliação e avaliação externa, definidas no projeto de Avaliação SINAES da IES;

- integrar com os demais instrumentos de avaliação do SINAES;

- detalhar a avaliação externa, em sintonia com as orientações da CONAES;

- elaborar relatórios parciais ou finais da avaliação interna e externa. 
A VEZ E A VOZ DOS COORDENADORES DAS CPAS DAS IES DE CAMPINAS QUE INTEGRAM O SINAES

- revisar o Projeto de Avaliação SINAES da IES e replanejar as atividades para a continuidade do processo de avaliação SINAES.

A terceira etapa é de consolidação, em que os resultados dos trabalhos realizados, durante todo o processo avaliativo, são consolidados. Para que essa etapa se concretize de maneira efetiva, algumas medidas são fundamentais, sendo elas: a elaboração de relatório, a divulgação dos resultados dos trabalhos e o balanço crítico do processo de auto-avaliação.

O relatório final da avaliação interna, segundo o SINAES (2004c), deve expressar, com clareza, o resultado das discussões, da análise dos dados e interpretação das informações, em especial do processo de autoavaliação. É relevante que esse relatório seja capaz de incorporar, quando disponíveis, os resultados do ENADE e da avaliação de cursos. Os destinatários desse documento são a comunidade acadêmica, os avaliadores externos e a sociedade, sendo desejável que ele apresente as sugestões de ações a serem desenvolvidas pela IES para minimizar seus pontos fracos e potencializar os fortes.

A divulgação dos resultados dá continuidade ao processo avaliativo o qual deve ser participativo e transparente - tornando público os resultados e as discussões das etapas anteriores e também as ações concretas provenientes dos resultados do processo avaliativo. Essa divulgação pode ser realizada junto à comunidade acadêmica por meio de reuniões, documentos informativos, seminários, palestras, entre outros (SINAES, 2004c).

Para o SINAES (2004c), o balanço crítico é uma reflexão sobre o processo de auto-avaliação objetivando a sua continuidade. Dessa maneira, uma análise das estratégias utilizadas, das dificuldades encontradas e dos avanços conquistados, durante todo o processo, possibilitará o planejamento de ações futuras. Assim sendo, o processo de auto-avaliação além de propiciar o autoconhecimento das IES, será, também, um balizador da avaliação externa, próxima etapa da AI prevista no SINAES.

\section{b) Avaliação Externa das Instituições}

A avaliação externa é realizada por comissões designadas pelo INEP, segundo diretrizes estabelecidas pela CONAES. O processo de avaliação externa tem como referência os padrões de qualidade para a educação superior contidos nos instrumentos de avaliação e nos relatórios das autoavaliações realizadas pelas CPAs. Esse tipo de avaliação, segundo o SINAES, deve se orientar por uma visão multidimensional, buscando inte- 
grar a sua natureza formativa e de regulação numa perspectiva de globalidade.

Em fevereiro de 2006, o Ministério da Educação lançou um documento intitulado "Avaliação Externa das instituições de educação superior: diretrizes e instrumentos" que servirá de guia para o processo de avaliação externa das IES.

Segundo esses documentos, o processo de avaliação externa é composto por duas etapas: I) a visita dos avaliadores in loco; e II) a posterior elaboração do relatório de AI. Esse relatório é enviado à CONAES para a elaboração de seu parecer conclusivo quanto à instituição avaliada.

Se o resultado da avaliação for considerado insatisfatório, de acordo com a Lei $n^{\circ} 10.861 / 2004$, o Ministério da Educação e a respectiva IES, devem celebrar um Protocolo de Compromisso para reverter essa situação.

A avaliação externa será a próxima etapa do SINAES a ser implementada em breve, pois todas as IES já realizaram seu processo de autoavaliação, de acordo com o prazo estipulado, e, agora, estão aguardando o agendamento da visita das comissões externa para a realização dessa outra fase da AVALIES.

No SINAES, a avaliação interna e a externa, assim como os demais instrumentos desse sistema, não se excluem, mas, sim, se combinam e se complementam.

Dessa forma, a vinda da Comissão para a Avaliação externa é uma etapa bastante importante, uma vez que o sistema é relativamente novo e há muitas dúvidas quanto a sua concepção e funcionamento. Devido a isso, entre outros fatores, muitas vezes os resultados apurados podem ser distorcidos por interpretação equivocadas de conceitos, uso incorreto de instrumento, tratamento inadequado dos dados, etc.

Há, também, que se considerar que, em alguns casos, devido ao fato das pessoas que conduziram a auto-avaliação estarem acostumadas com certos acontecimentos na instituição, e que, portanto, fazem parte de sua rotina, elas podem não conseguir observar certas coisas com imparcialidade ou de forma mais abrangente.

\section{IV) Outros Instrumentos}

O SINAES propõe uma AI integrada por diversos instrumentos complementares, entre eles existem os instrumentos que auxiliam na coleta de informações. 
A VEZ E A VOZ DOS COORDENADORES DAS CPAS DAS IES DE CAMPINAS QUE INTEGRAM O SINAES

Esses instrumentos auxiliares, e que estão integrados ao SINAES, são o Censo da Educação Superior e o Cadastro de Cursos e Instituições, incluindo-se aqui o cadastro de docentes.

O Censo é apresentado de forma detalhada aos gestores de políticas educacionais a fim de lhe propiciar uma visão das tendências de um nível de ensino em processo de expansão e diversificação. Ele é realizado anualmente, e coleta vários dados da educação superior brasileira, incluindo cursos de graduação (presenciais e a distância) e informações sobre atividades de extensão das IES por meio de questionários eletrônicos respondidos via Internet. Sua finalidade é fazer uma radiografia da educação superior (INEP 2006c).

O Cadastro de Cursos e Instituições, coleta permanentemente as informações sobre as IES e seus cursos, também por meio de formulários eletrônicos preenchidos pela Internet.

No portal disponibilizado pelo MEC/INPE, pode-se encontrar IES de todo o país, reunindo várias informações para a sociedade, tais como: tipos de instituições, tipos de cursos, situação legal, avaliação dos cursos e das instituições entre outros.

O Cadastro Nacional de Docentes foi instituído pela Portaria $n^{\circ} 327 /$ 05, e trata-se de um sistema informatizado de dados e informações relativas aos docentes dos cursos ministrados pelas IES que estão sob o gerenciamento do INEP. As IES são responsáveis pela atualização e validação dos dados e informações, por meio de um formulário eletrônico. O certificado de validação é pré-requisito para adesão ao Programa de Financiamento Estudantil - FIES e Programa Universidade para Todos - PROUNI, bem como abertura de processos de credenciamento e recredenciamento de IES e os relativos à autorização e reconhecimento de cursos.

O que ocorre na prática é que as IES preenchem os dados dos docentes, no site em um período estipulado pelo INEP, anualmente, e os professores recebem um e-mail do próprio site (Portal SINAES), com login e senha, solicitando que confirmem as informações prestadas pelas IES. Ao concluir a confirmação de seus dados, cada docente recebe um protocolo e a IES só finaliza o seu processo quando todos os docentes efetivarem essa confirmação de dados constantes no cadastro previamente preenchido pela IES.

É importante destacar que, segundo o SINAES (2006), nesse sistema avaliativo a integração dos instrumentos - auto-avaliação, avaliação externa, avaliação das condições de ensino, avaliação de desempenho dos estu- 
dantes, censo da educação superior e cadastro das IES e cursos - possibilitam a atribuição de conceitos, ordenados em cinco níveis, a cada uma das dimensões preconizadas no SINAES e ao conjunto das dimensões avaliadas nas IES.

\section{A Comissão Própria de Avaliação (CPA)}

A CPA é uma Comissão formada por representantes dos docentes, técnico-administrativos e discentes de cada IES e também da sociedade civil organizada, responsáveis pelo processo de avaliação interna nas suas respectivas instituições de ensino, conforme determina a Lei $n^{\circ} 10.861 /$ 2004.

A constituição de uma CPA, no âmbito de cada instituição e sua forma de composição, está estabelecida na Portaria n ${ }^{\circ}$ 2.051/04, em seu artigo $7^{\mathrm{o}}, \S 2^{\mathrm{o}}$ :

A forma de composição, a duração do mandato de seus membros, a dinâmica de funcionamento e a especificação de atribuições da CPA deverão ser objeto de regulamentação própria, a ser aprovada pelo órgão colegiado máximo de cada instituição de educação superior, observando-se as seguintes diretrizes:

I - necessária participação de todos os segmentos da comunidade acadêmica (docente, discente e técnico-administrativo) e de representantes da sociedade civil organizada, ficando vedada à existência de maioria absoluta por parte de qualquer um dos segmentos representados;

II - ampla divulgação de sua composição e de todas as suas atividades.

A CPA tem como atribuição coordenar os processos internos de avaliação da instituição, de sistematizar e de prestar as informações solicitadas pelo INEP, ressaltando que ela deve atuar com autonomia em relação a conselhos e demais órgãos colegiados existentes na IES (CONAES, 2004).

Os trabalhos das CPAS devem ser realizados segundo etapas e procedimentos estabelecidos nos documentos da CONAES e do INEP, conforme já detalhado no tópico anterior.

Dessa forma, alguns aspectos práticos desse trabalho de auto-avaliação coordenado pela CPA, e que ainda não foram mencionados por não constarem dos documentos oficiais, também merecem ser ressaltados, para que se possa ter uma visão sistêmica de seu funcionamento. 
A VEZ E A VOZ DOS COORDENADORES DAS CPAS DAS IES DE CAMPINAS QUE INTEGRAM O SINAES

Um aspecto a ser destacado é o papel que o coordenador da CPA exerce nesse formato proposto. Ele é um ator essencial na condução desse processo de auto-avaliação visto que, regra geral, foi ele quem teve os primeiros contatos com o material divulgado pelo governo, participou das oficinas realizadas pelo MEC e, depois, foi quem atuou como multiplicador do que absorveu sobre o novo sistema avaliativo que estava sendo instituído junto aos demais membros da comunidade acadêmica.

A condução dos processos de avaliação é complexa e exige tempo e dedicação por parte dos integrantes da CPA. É um trabalho voluntário no qual os membros não têm um horário específico para isso, tendo de conciliálo com os demais compromissos profissionais e pessoais. Algumas IES possuem departamentos específicos para cuidar de avaliação, ou seja, contratam pessoas para esse fim e as denominam de equipes de apoio para os trabalhos coordenados pelas CPAs.

Para que o trabalho da CPA se consolide e se torne uma cultura de avaliação, e não um mero processo para se cumprir a legislação, é preciso que exista entre os seus membros o princípio de participação em processos de autoconhecimento institucional, e, aos poucos, a avaliação institucional se transforme na Avaliação Participativa defendida por Leite (2005) que pressupõe a existência de uma democracia forte para ser realizada.

O SINAES iniciou um trabalho para que se crie nas IES uma cultura de avaliação nas instituições. Todavia, isso leva tempo, pois é preciso que haja o amadurecimento desse novo processo avaliativo, se consiga "apagar" esse pré-conceito a respeito da avaliação e ir semeando, aos poucos, essa nova cultura avaliativa, não punitiva, mas, sim, formativa.

\section{Desvelando as CPAS das IES de Campinas}

Realizou-se um trabalho de pesquisa, junto aos coordenadores das CPAs das IES de Campinas que integram o SINAES, com a finalidade de se conhecer um pouco mais a respeito dos trabalhos coordenados pelas CPAS, quem são os coordenadores das CPAs; comparar a concepção avaliativa do coordenador da CPA com a concepção do SINAES; identificar as expectativas do coordenador em relação ao SINAES; entre outros.

Foram realizadas com esses sujeitos entrevistas presenciais, utilizando-se um roteiro semi-estruturado como instrumento de coleta de dados e no tratamento dos dados, utilizou-se a análise de conteúdo. 
Alguns dos resultados dessa pesquisa serão apresentados a seguir, com o intuito desvelar o que de fato acontece na CPA das IES de Campinas, ou seja mostrar essa fase do SINAES na prática.

\section{a) O coordenador e a formação da CPA}

Todos os coordenadores das CPAs foram nomeados pelos dirigentes máximos das suas instituições. Pode-se dizer que os coordenadores das CPAs são pessoas de confiança dos dirigentes da instituição, ocupando cargos de destaque e/ou estando na instituição há bastante tempo, se considerarmos a existência das respectivas instituições.

Uma pessoa de confiança da instituição não é condição suficiente para atuar como coordenador da CPA, mas poderá ajudá-lo à medida que ela terá maior apoio por parte dos dirigentes.

O coordenador não precisa, necessariamente, ser um especialista no assunto, mas deve ter a capacidade de fazer articulações e incorporar o novo sistema avaliativo.

Ao se analisar a composição das CPAs, nota-se que em apenas dois casos ela permanece a mesma, se comparada com a primeira formação. Contudo, ao se tratar de seus coordenadores, constatou-se que eles são os mesmos, desde o início, em nove das IES, e onde houve mudança, coincidentemente ela se deu devido ao fato de os mesmos não trabalharem mais em suas respectivas instituições de ensino.

Em quatro casos, os membros das CPAs foram nomeados na íntegra pelos seus dirigentes. Em cinco casos houve eleição para que se escolhessem os representantes de cada segmento e duas IES não informaram como isso ocorreu.

Em todos os casos há um equilíbrio entre a representatividade dos segmentos docente, discente, técnico-administrativo e sociedade civil, respeitando o que reza a Lei $\mathrm{n}^{\circ}$ 10861/04 em seu artigo 11, que menciona ser vedada a formação que dê privilégio à maioria absoluta de um dos segmentos representados.

\section{b) O coordenador e a condução dos trabalhos}

O coordenador da CPA tem um papel fundamental nesse processo, pois foi ele quem estudou o material divulgado pelo governo e quem participou das oficinas realizadas pelo MEC. Posteriormente, funcionou como um multiplicador desse material, estando sempre atento às etapas subse- 
qüentes, fazendo reuniões com sua equipe, ou seja, é ele quem alimenta o processo e o faz acontecer.

Em todas as IES, de uma forma geral, o que ocorreu na prática foram reuniões para leitura e discussão dos documentos do SINAES e a elaboração dos respectivos Projetos de Avaliação Institucional enviados ao Ministério da Educação. O trabalho de cada CPA foi realizado a partir da aprovação desse projeto, seguiu-se o que nele estava determinado, e as etapas estipuladas pelo SINAES.

Devido ao fato do SINAES ser muito recente e a auto-avaliação, nos moldes que ele propõe, ser uma novidade para as instituições, nota-se uma certa insegurança, uma certa dificuldade por parte dos coordenadores em conduzir o processo de auto-avaliação, o que é perfeitamente normal na primeira vez em que se realiza um determinado trabalho.

Nas entrevistas, procurou-se identificar quais os tipos de dados coletados, como foram coletados e de que maneira foram tratados.

De acordo com os coordenadores, dez instituições coletaram tanto dados quantitativos quanto dados qualitativos, sendo que apenas uma optou em coletar dados exclusivamente quantitativos.

Os instrumentos que as instituições utilizaram para coletar os dados em dez casos foram os questionários, uma não informou o instrumento utilizado e, algumas, também consultaram documentos já existentes na instituição para auxiliá-las nessa fase dos trabalhos.

A coleta e tratamento dos dados, em geral, são realizados pela própria CPA, e duas instituições mencionaram que possuem departamentos que auxiliam os trabalhos das CPAS, inclusive no tratamento de dados.

Um aspecto questionado ao se comentar o processo de trabalho foi a autonomia. Nesse quesito, todos os coordenadores declararam que tiveram autonomia e liberdade de atuação, porém ela não ficou tão evidente em algumas falas:

Observa-se certo policiamento nas falas de alguns entrevistados e percebe-se, por meio das conversas informais, que existem CPAs que não têm autonomia para trabalhar.

Ao se analisar as respostas sobre o que os coordenadores consideravam como pontos positivos do trabalho da CPA, enquanto equipe, notouse uma convergência para o empenho de seus membros na realização do trabalho.

Destaca-se porém que, não basta que os membros participem, é preciso que eles tenham consciência de que a auto-avaliação deve ser realizada 
porque é importante para a comunidade à medida que deve provocar melhorias na instituição, devendo, os mesmos, atuar como protagonistas no processo.

De acordo com todos os coordenadores, os resultados obtidos na autoavaliação, de fato, retrataram a realidade da sua instituição.

Dessa maneira, devido ao fato de a auto-avaliação espelhar a realidade da instituição, não houve grandes surpresas na divulgação dos resultados junto à comunidade acadêmica, segundo os coordenadores.

Nesse aspecto, ressalta-se que a auto-avaliação não deve gerar surpresa, mas, sim, conseqüências, ações para melhorar as condições acadêmicas de ensino na instituição. E, ainda, se já estavam cientes, antes de conhecer os resultados apurados pela CPA, da situação que se encontrava a IES, os responsáveis deveriam ter tomado providências no sentido de corrigir as suas fragilidades.

\section{c) O coordenador e a Avaliação Institucional}

Nas entrevistas, buscou-se identificar qual era a concepção de avaliação institucional do entrevistado, para que serve a AI e quais são os seus prós e contras.

Em síntese, para os coordenadores, a Avaliação Institucional é concebida como um importante mecanismo auxiliar para que a instituição possa ter uma visão da sua situação, e assim possa implementar algumas ações, a fim de melhorar as suas condições acadêmicas. Comentam, ainda, que, se ela não for bem trabalhada, pode trazer distorções, e, por isso, deve ser um momento de conscientização e de reflexão por parte dos envolvidos.

Nesse aspecto, nota-se que, apesar da importância da Avaliação Institucional, o que falta na educação superior é a cultura de avaliação que é historicamente construída. Dessa forma, as IES têm um longo caminho a percorrer para que, de fato, esse tipo de avaliação cumpra seu papel e espera-se que o SINAES colabore para que isso ocorra.

\section{d) O coordenador e a Auto-Avaliação Institucional}

Neste trabalho, procurou-se identificar junto aos coordenadores quais foram as maiores dificuldades para se realizar o processo de auto-avaliação, o significado dessa auto-avaliação para ele e seu sentimento ao concluir a avaliação interna.

Os coordenadores, em síntese, comentaram que o processo de autoavaliação nas IES demandou muito tempo por parte dos membros da CPA 
para o seu entendimento e operacionalização, e a falta desse tempo "extra" foi algo que teve de ser bem trabalhado na equipe. Além do tempo, os principais desafios foram a elaboração de instrumentos adequados para a coleta de dados bem como o tratamento dos mesmos. Esse processo trouxe um conhecimento maior sobre o quadro da instituição e gerou um sentimento de satisfação ao ser concluído.

Nesse sentido, uma das maiores dificuldades percebidas diz respeito à mudança de comportamento por parte das pessoas envolvidas, ou seja, o pré-conceito que possuem em relação à avaliação, sempre associado-a ao valor de troca, tanto seja à punição, quanto à premiação.

\section{e) O coordenador e o SINAES}

Entre os coordenadores, nove acreditam que o SINAES tem tudo para dar certo, que precisa de ajustes, mas estão confiantes no sistema.

No SINAES, assim como em qualquer processo em fase de implementação, há necessidade de adequações, pois por melhor que seja o seu planejamento na teoria, somente quando esse processo é colocado em prática é que se percebe as suas falhas e, assim, os ajustes vão sendo gradualmente implementados na medida em que são necessários.

Sintetizando os comentários dos entrevistados, devido ao fato de o SINAES ser um sistema novo e estar em fase de implementação, não há como se ter certeza a respeito da sua eficiência. Todavia, acreditam que esse sistema avaliativo tem tudo para dar certo e esperam que haja a continuidade do processo. Apesar da importância da visita da Comissão Externa, nota-se uma expectativa sobre o seu comportamento, ou seja, se ela virá para contribuir ou para punir. Apontam o ENADE como um componente importante do sistema, e comentam que esse exame representa uma evolução se comparado com o Provão, à medida que busca verificar a contribuição da IES para com a formação do educando, ao aplicar a prova em dois momentos, no início e no término do curso.

Nas entrelinhas, a leitura que se pode fazer é que se, o SINAES for extinto, as IES voltam a se comportarem da mesma maneira que faziam antes dele existir, pois parecem avaliar para o sistema verificar e não para beneficiar a comunidade com a melhora da educação superior.

\section{f) As IES e a Avaliação institucional.}

As instituições que realizavam avaliação institucional antes do SINAES, a desempenhavam de forma fragmentada, uma vez que a maioria 
considerava, apenas, a opinião dos discentes e parte das dimensões propostas atualmente, o que fez com que houvesse um avanço no processo de Avaliação.

No que diz respeito aos trabalhos atuais das instituições, em relação ao SINAES, as mesmas estão tentando se enquadrar nos moldes desse sistema avaliativo, no que tange às dimensões, e estão revendo seus instrumentos de coleta de dados com vistas a aprimorá-los cada vez mais.

Em suma, os coordenadores afirmaram que as instituições que já faziam avaliação institucional perceberam a necessidade de aperfeiçoar os mecanismos avaliativos já existentes. As que não a realizavam, começaram a fazê-la para atender ao que estava sendo proposto no SINAES.

\section{Considerações Finais}

Este artigo, resultado de um trabalho de pesquisa, procurou conhecer como as instituições de ensino superior de Campinas, por meio de suas Comissões Próprias de Avaliação, conduziram os trabalhos de auto-avaliação. Para tal, foram entrevistados os coordenadores dessas comissões, uma voz importante nesse processo.

É oportuno destacar que, em momento algum, houve a pretensão de esgotar a discussão sobre essa temática ou responder definitivamente as questões suscitadas, em especial devido à complexidade do assunto e a recente implantação do SINAES.

O atual sistema avaliativo da educação superior é uma política de Estado que tem caráter de regulação e emancipação.

O SINAES se tornou misto porque sofreu pressão de vários lados e, para que ele começasse a funcionar, algumas concessões foram feitas. Infere-se que a própria forma de constituição da CPA foi uma dessas concessões, pois apesar de estar assegurada na legislação a autonomia das CPAS, com relação às atribuições de condução dos processos de avaliação internos e de prestação de informações solicitadas pelo INEP, não se pode ignorar a formação dessa comissão.

Em todas as instituições de ensino superior de Campinas, de acordo com os dados coletados, os coordenadores das CPAs foram nomeados pelos dirigentes máximos das instituições.

Esses coordenadores, em sua totalidade, ocupam cargos de confiança nas IES e ou são pessoas da confiança dos dirigentes. Contudo, é importante destacar que isso não é condição suficiente para que ele ocupe a co- 
ordenação da CPA, diante do papel que ele deve exercer no processo de auto-avaliação. Nesse aspecto, salienta-se a importância do coordenador da CPA nesse modelo, pois para o SINAES ele é o disseminador do sistema junto às bases.

Como regra geral, foi o coordenador da CPA quem teve os primeiros contatos com o material divulgado pelo governo, participou das oficinas realizadas pelo MEC e, depois, atuou como multiplicador do que absorveu a respeito do SINAES junto aos membros da comissão da sua instituição.

O coordenador da CPA não deve ser uma pessoa que simplesmente repasse, à sua comissão, a informação que obteve nos treinamentos, não é qualquer um que deve atuar/ocupar esse cargo. O coordenador precisa comunicar aquilo que o SINAES quer, e a maneira como ele faz isso é de suma importância. Ele não deve atuar como um tradutor da política, mas, sim, como seu intérprete. Ele deve resignificá-la, acreditar no sistema e, dessa forma, motivar a comissão nesse processo de auto-avaliação.

A auto-avaliação é entendida no SINAES, como um processo cíclico, criativo e renovador de análise e síntese das dimensões que definem a instituição. E para que esse processo tenha êxito, não é suficiente a existência de um coordenador que tenha feito um "curso" ou que a instituição tenha uma CPA constituída, o que de fato importa e faz toda diferença é como os envolvidos no processo o concebem, ou seja, qual o significado da autoavaliação para eles.

Não basta que os membros participem do processo, é preciso que eles tenham consciência de que a auto-avaliação deve ser realizada, porque é importante para a comunidade à medida que deve provocar melhorias na instituição, devendo os mesmos atuar como protagonistas nessa etapa do sistema avaliativo.

Para que o sistema funcione, quem avalia deve incorporar esse novo conceito proposto pelo SINAES, pois de nada adiantará ele estar munido de um novo sistema, com novos instrumentos, se não souber fazer a leitura dos dados que irá avaliar segundo essa nova concepção.

A falta de uma cultura de avaliação nas IES, é uma das maiores dificuldades que o SINAES está enfrentando para a realização da auto-avaliação, e essa falta de cultura avaliativa é mencionada nos documentos de implantação do SINAES.

De acordo com a CONAES (2004), o processo contínuo de auto-avaliação será um instrumento de construção e ou consolidação da cultura de avaliação na instituição, onde a comunidade interna se identifique se com- 
prometa. O caráter formativo deve possibilitar o aperfeiçoamento tanto pessoal dos membros da comunidade acadêmica, quanto institucional, pelo fato de fazer com que todos os envolvidos se coloquem em um processo de reflexão e autoconsciência institucional.

Para que o trabalho da CPA se consolide e se torne uma cultura de avaliação, e não um mero processo para se cumprir a legislação, é preciso que exista entre os seus membros o princípio de participação em processos de autoconhecimento institucional.

O SINAES representa um grande avanço para a avaliação da educação superior brasileira, não apenas no que tange a cultura de avaliação nas IES, mas, também, por possibilitar o autoconhecimento das instituições de uma forma abrangente, pois não se pode melhorar aquilo que se desconhece.

As instituições que já faziam avaliação institucional, segundo os dados coletados, perceberam a necessidade de aperfeiçoar os mecanismos avaliativos já existentes. E as que não a realizavam começaram a fazê-la para atender o que estava sendo proposto no SINAES, ampliando suas dimensões avaliativas.

O SINAES iniciou um processo para que se crie e se consolide uma cultura de avaliação em nosso país. Há um longo caminho a percorrer. É um percurso árduo, pois toda mudança esbarra em resistências e requer tempo para ser assimilada. Contudo, é preciso que isso seja trabalhado de forma constante, pelas IES e também pelo MEC, uma vez que é preciso semear aos poucos e continuamente essa nova cultura avaliativa não punitiva, mas, sim, formativa e, quem sabe até mesmo participativa.

Sugere-se uma ampla divulgação das informações do SINAES, não só na forma de documentos, mas principalmente por meio de oficinas constantes visando a aproximação das instituições aos propósitos da política educacional, para que todos possam estar em sintonia, uma vez que o que se pretende é um objetivo comum em benefício de todos, a melhoria da educação superior brasileira. 
A VEZ E A VOZ DOS COORDENADORES DAS CPAS

DAS IES DE CAMPINAS QUE INTEGRAM O SINAES

\section{REFERÊNCIAS}

BALZAN, Newton Cesar. A voz do estudante: sua contribuição para a deflagração de um processo de avaliação institucional. In: BALZAN, Newton Cesar; DIAS SOBRINHO, José (Orgs). Avaliação Institucional: teoria e experiências. São Paulo: Cortez, 1995.

COMISSÃO NACIONAL DE AVALIAÇÃO DA EDUCAÇÃO SUPERIOR. CONAES. Diretrizes para a Avaliação das instituições de educação superior. Brasília: Ministério da Educação, 2004.

CUNHA, Luiz Antônio. Ensino Superior e universidade no Brasil. In: LOPES, Eliane Marta Teixeira et al. (Orgs.). 500 anos de educação no Brasil. 2.ed. Belo Horizonte: Autêntica, 2000.

DIAS SOBRINHO, José. Educação e avaliação: técnica e ética. In: DIAS SOBRINHO, José ; RISTOFF, Dilvo I. (Orgs.). Avaliação democrática: para uma universidade cidadã. Florianópolis: Insular, 2002.

Avaliação: políticas educacionais e reformas da educação superior. São Paulo: Cortez, 2003a.

GARIBA JUNIOR, Maurício. Um modelo de avaliação de cursos superiores de tecnologia baseado na ferramenta Benchmarking. 2005. Tese (Doutorado) - Universidade Federal de Santa Catarina, Florianópolis, SC, 2005.

INSTITUTO NACIONAL DE ESTUDOS E PESQUISAS EDUCACIONAIS ANÍSIO TEIXEIRA. INEP. Informações sobre o ENADE. Disponível em: $<$ http://www.inep.gov.br/superior/enade/default. asp>. Acesso em: 20 nov. 2006a.

INSTITUTO NACIONAL DE ESTUDOS E PESQUISAS EDUCACIONAIS ANÍSIO TEIXEIRA. INEP. Avaliação dos cursos de graduação. Disponível em: <http://www.inep.gov.br/superior/condicoesdeensino>. Acesso em: 21 nov. 2006b.

INSTITUTO NACIONAL DE ESTUDOS E PESQUISAS EDUCACIONAIS ANÍSIO TEIXEIRA. INEP. Censo da Educação Superior. Disponível em: $<$ http://www.inep.gov.br/superior/censosuperior/default.asp >. Acesso em: 21 nov. $2006 \mathrm{c}$.

INSTITUTO NACIONAL DE ESTUDOS E PESQUISAS EDUCACIONAIS ANÍSIO TEIXEIRA. INEP. ENADE 2007 avaliará 16 áreas do conhecimento no dia 11 de novembro. Disponível em: <http://www.inep.gov.br/ imprensa/noticias/edusuperior//enade/news07_05.html>. Acesso em: 17 jul. 2007. 
LEITE, Denise. Reformas universitárias: avaliação institucional participativa. Petrópolis: Vozes, 2005.

PAULA, Maria de F. ; AZEVEDO, Marcela Davino de. A avaliação institucional na universidade: o caso UFF. Avaliação: Revista da Rede de Avaliação Institucional da Educação Superior - RAIES, Campinas, SP, n. 3, p. 51-73. set. 2004.

RISTOFF, Dilvo I. Avaliação institucional: pensando princípios. In: BALZAN, Newton Cesar ; DIAS SOBRINHO, José (Orgs). Avaliação Institucional: teoria e experiências. São Paulo: Cortez, 1995. p. 37 - 51.

RISTOFF, Dilvo I. ; LIMANA, Amir. O ENADE como parte da avaliação da educação superior. Disponível em : <http://inep.gov.br/imprensa/artigos/ artigos/enade.html> . Acesso em : 23 abr. 2007.

ROTHEN, José Carlos; SCHULZ, Almiro. SINAES: do documento original à legislação. Disponível em: < http://anped.gov.br/reunioes/28/textos/gt11/ gt1119int.doc >. Acesso em : 18 mar. 07

SISTEMA NACIONAL DE AVALIAÇÃO DA EDUCAÇÃO SUPERIOR. SINAES: bases para uma nova proposta de avaliação da educação superior. Brasília, DF: INEP, 2004a.

SISTEMA NACIONAL DE AVALIAÇÃO DA EDUCAÇÃO SUPERIOR. SINAES: da

concepção à regulamentação. 2.ed. ampl. Brasília, DF: INEP, 2004b.

SISTEMA NACIONAL DE AVALIAÇÃO DA EDUCAÇÃO SUPERIOR. SINAES: roteiro de auto-avaliação institucional 2004 - orientações gerais. Brasília, DF: INEP, 2004c.

SISTEMA NACIONAL DE AVALIAÇÃO DA EDUCAÇÃO SUPERIOR. SINAES. Disponível em :<http://www.inep.gov.br/sinaes $>$. Acesso em: 21 set. .2006a.

SISTEMA NACIONAL DE AVALIAÇÃO DA EDUCAÇÃO SUPERIOR. SINAES: avaliação externa das instituições de educação superior - diretrizes e instrumentos. Brasília, DF:INEP, 2006b 